\section{Flight of Birds Across the Moon's Disc.}

ON the evening of October 7, I 895 , while observing the passage of the moon through the Pleiades for occultations, my attention was attracted by a fight of birds across the moon's disc. This continued with more or less regularity the whole time I was at work, from 7.30 to 9.30 , the birds usually crossing singly, but sometimes in groups of two, three, or even four. In all, I saw perhaps 50 or 60 ; assuming a like frequency during the intervals when I was not at the telescope, from 200 to $25^{\circ}$ must have crossed the disc during the two hours. All were flying south with a single exception. Their outlines and the flapping motions of their wings were very distinct; none were soaring. The telescope is a 12 -inch refractor: eyepiece of power 9o. The moon was low, its altitude ranging from $5^{\circ}$ to $15^{\circ}$.

The time occupied in transit varied from four to eight seconds, the difference in apparent size being very marked, and the larger always taking the less time. Assuming a rate of twenty miles an hour for their flight, the distance would be about 5 miles for a bird making a transit in eight seconds, or $2 \frac{1}{2}$ miles for four seconds. Taking into consideration the altitudes of the moon when the above transits were timed, the corresponding altitudes of the birds above sea-level ranged from 2700 to 5000 feet. Considerations as to its size make it probable that these figures are none too small. It may be of interest to note that the Observatory stands on a promontory jutting out about 5 miles from the general trend of the Syrian coast, and that according to these calculations the birds were flying either just along the coast-line or over the sea.

I may add that, in addition to Mr. Bray's experience, given in NATURE, No 1348, several accounts of similar observations are given in Newton's "Dictionary of Birds," with estimates of altitudes, ranging, for the most part, much higher than those given above.

ROBERT H. WEST.

Syrian Protestant College, Beirut, November 25.

\section{A Luminous Centipede.}

RETURNING home on a very dark evening a few days ago, I saw on the ground a greenish phosphorescent light which, in the distance, I took to be a glowworm (Lampyris noctiluca), but a nearer approach showed a luminous thread-like worm of $\mathbf{I} \frac{1}{4}$ inches in length, moving in curves along the gravel drive. I stooped and placed a finger and thumb on either side of the glowing thread without actually touching it, and in a few seconds observed that, aware of danger either from scent or vibration, the insect showed a remarkable power of control over its luminosity, invaluable for protection. It began to extinguish its light, and in a most peculiar fashion not dying slowly out all over, but with a rapid wave of darkness sweeping from the tail to the head, then in a second or so glowing brightly all over again, repeating the manouvre several times so long as my finger and thumb remained in its vicinity. A glass was brought, into which I transferred the insect, where it glowed with a lessened light for three or four hours. The next night the phosphorescence was very feeble, and on the morning following the insect was dead.

Seen in the daylight my capture appeared to be a thin threadlike centipede, orange coloured, furnished with a fringe of fine hairs on either side of its many-segmented body.

Rose Haig Thomas.

The White House, Basildon, November 27.

THE above communication certainly refers to one of the luminous centipedes of the family Geophilida; and since the species that most commonly draws attention to itself in England by the exhibition of phosphorescence is of a reddish-orange colour and is known as Linotienia crassipes, there is no reason to doubt that the specimen under discussion was an example of this species. The property of luminosity lies in an adhesive fluid secreted by glands which open upon the lower surface of the body, and the power of discharging or retaining the fluid appears to be entirely under the centipede's control.

The phenomenon is observable during the autumn months, from about the middle of September to the end of November, and although its significance is not clearly understood, it is generally believed to be connected with the pairing of the sexes.

R. I. Pocock.
The Critical Temperature of Hydrogen.

In the October number of the Proc. Phys. Soc., Mr. "G. H. B.," after quoting Wroblewski's paper "Die Zusam. mendriickbarkeit des Wasserstoffes" (Wiener Sitzb., I 889), says (referring to my paper "On the Critical Temperature of Hydrogen," Bull. Acad. Cracoi'ie, March i 895): "Natanson does not appear to have made any fresh experiments on the subject, and the conclusions arrived at in his paper are therefore not results of independent original investigation." It is difficult to understand the right $\mathrm{Mr}$. "G. H. B." has to ignore the professedly theoretical character of my paper. To blame a writer offering theoretical deductions on the account of his not having made "fresh experiments," is surely a criticism of extraordinary character. Wroblewski's critical data are not in the least the outcome of direct experiment, but have been calculated from an empirical equation, constructed to represent Wroblewski's compressibility curves. My reasoning and calculation are utterly different, being founded upon Van der Waals' law of thermodynamic correspondence. Besides, there are other points in my paper, and they have no relation with whatever Wroblewski has written. All this will be seen at once on comparing my paper with that of Wroblewski's. But from Mr. G. H. B.'s own words, it must be inferred that, before publishing what implies a serious accusation, he did not take the trouble of looking with his own eyes at Wroblewski's paper.

Cracow University, November 28.

\section{LADISIAS NATANSON.}

\section{A METEOR PHOTOGRAPH.}

THE accompanying photograph (p. I32) was obtained on Saturday night, November 23 , about $12 \mathrm{~h}$. $15 \mathrm{~m}$., by Mr. C. P. Butler, at Knightsbridge. With the intention of focussing and testing the field of a new lens, he had placed a quarter-plate camera on the window-sill, pointed it roughly at the region near the boundaries of Perseus, Andromeda, and Aries. He was necessarily in darkness during the exposure, but uncovered the plate about $12 \mathrm{~h}$. Iom., and terminated the exposure at $12 \mathrm{~h}$. 2om., so that the limits are close enough for recognising the meteor if it chances to have been recorded elsewhere, On developing the plate on the following Monday, the track of the meteor was the first impression to be perceived, and, not knowing of its occurrence during the taking of the photograph, it was thought that the plate had by some mishap been spoiled. Having finished developing, however, and after fixing, it was seen that this was not the case, the strange appearance being evidently an image of some meteor flashing past during the exposure. The star trails (the camera was fixed, so the stars are represented by short lines about an eighth of an inch long) are all distinct, but owing to the region included in the field being almost barren of bright stars, with the exception of $a, \beta$, and $\gamma$ Arietis, which come in at the edge of the plate, they are too minute to bear reproduction.

Confirmation of the occurrence of the meteor is given by its having been observed from the South Kensington Observatory, both the time of fall, $12 \mathrm{~h}$. $15 \mathrm{~m}$., and the estimated region of its path being identical with the above observations.

As near as can be estimated, on consulting the region on the star map, the meteor appeared some distance south of the interval between Perseus and Aries, in the area enclosed by $a, \gamma, \xi^{2}$ Ceti, and fell downwards. It would probably be one of the Andromedes, which were due to occur on the 23 rd ult.

It was described as being as bright as Jupiter, and leaving a long trail. This is fully borne out on carefully examining the negative, or the accompanying enlargement, which is about six times the size of the original. Much additional light is thrown on the phenomena attending the passage of a meteorite through our atmosphere, as at present all that is known rests on the results of visual observations, which may be greatly deceptive in the case of such rapidly-moving objects.

The image, in comparison with those of stars of known

No. 1363, VงL. 53] 